\title{
Multi Layer Perceptron Modelling in the Housing Market
}

\author{
KU RUHANA KU MAHAMUD, AZURALIZA ABU BAKAR \\ \& NORITA MD. NORWAWI \\ School of Information Technology \\ Universiti Utara Malaysia
}

\begin{abstract}
The study examines the use of multi layer perceptron network (MLP) in predicting the price of terrace houses in Kuala Lumpur (KL). Nine factors that significantly influence the price were used in this attempt. Housing dat from 1994 to 1996 were presented to the network for training. Tested results from the model obtained for various years were compared using regression analysis. The study provides the predictive ability of the trained $M L P$ model that can be used as an alternative predictor in real estate analysis.
\end{abstract}

\begin{abstract}
ABSTRAK
Kajian ini menguji penggunaan rangkaian perceptron multi aras (MLP) untuk meramal harga rumah teres di Kuala Lumpur (KL). Sembilan faktor yang mempengaruhi harga secara signifikan digunakan. Data perumahan dari tahun 1994 hingga 1996 dipersembahkan kepada rangkaian untuk sesi latihan. Hasil ujian model yang diperoleh untuk beberapa tahun dibandingkan dengan kaedah regresi. Kajian ini menyediakan kebolehan peramalan bagi model rangkaian multi aras yang terlatih dan boleh digunakan sebagai alat peramal alternatif dalam analisis hartanah.
\end{abstract}

\section{INTRODUCTION}

The housing industry has been a very important sector in Malaysia's economic growth. House pricing consistently fluctuates in accordance with many factors. Housing developers classify the factors involved in determining prices into internal factors and external factors. Internal factors are marketing objectives, marketing mix strategy and cost, while external factors include market and demand, consumer perceptions of price and value, competitors' cost prices and offers, economic conditions which are non-linear, such as recession, inflation and interest rates, government policies and social concerns.

The unpredictable movement of prices in the housing industry has shown the need for a systematic model to overcome the problem of forecasting the price movement of houses in Malaysia. The ability to deal with non-linear factors which are found in the housing industry is a major advantage of artificial neural networks (ANNs) modelling. Other techniques such as regression and heuristics are unable to give a precise prediction in price movements as price movements forecasting is an example of the real world system in that they change over time.

ANNs have been shown to be successful as a predictive tool. One of the most commonly used ANNs tool for prediction, classification and forecasting is the multi layer perceptron (MLP). Some organizations have developed sophisticated systems that require the training of hundreds or even thousands of ANNs on a 
weekly basis to predict stock market index movements as well as individual stock price behaviour (Patterson, 1996). It has also been shown that neural network modelling is a more superior method compared with other techniques because of its ability to handle incomplete and noisy data (Hardgrave, Wilson \& Walstrom, 1994). Neural network is also preeminently suited to detect non-linear patterns without ex-ante knowledge of the underlying model (Baestaens, Van Den Bagh \& Wood, 1994).

Chapman (1994) discusses the development of a neural network model for use as part of a stock market trading system and some of the important considerations and decisions in the development of such systems. Some research examples using neural networks in stock market applications include forecasting the value of a stock or index, recognition of patterns in trading charts, prediction of ratings of corporate bonds, estimation of the market price of options, and direct generation of buy, sell and hold trading signals.

Richeson, Zimmerman and Barnett (1994) developed a neural network model to predict the payment performance on consumer loans by identifying loans as either performing or non-performing. The models help the loan officer function more efficiently by prescreening and eliminating unqualified applicants. The models can also assist the bank manager or auditor in evaluating how well the bank is adhering to its own credit standards.

Hardgrave et al. (1994) explored the biological inspired, non-parametric statistical approach of neural networks, in terms of their ability to predict academic success in an MBA program. They found that neural networks perform at least as well as traditional methods such as regression and discriminant analysis, and are worthy of further investigation. Saiful Hafizah et al. (1996) discussed the neural networks model for predicting the profitability of selected firms on the Kuala Lumpur Stock Exchange (KLSE). Their research employed MLP to achieve better results in predicting the profitability of listed companies in the KLSE.
In this paper, an original application of MLP modelling in the housing market is presented. To our knowledge, no studies have been done on the application of ANNs in the Malaysian housing industry. Furthermore MLP can be applied as a systematic and efficient forecasting method in non-linear problems for business applications.

\section{THE MODEL}

Neural networks are built of many nodes, called neurons or processing elements. Each node is a very simple unit which takes many inputs simultaneously and sums them. Each node produces a response dependent on the level of inputs received. If the sum of the inputs is high, the node reacts strongly; if the sum of the inputs is low, the response is low. This triggers an activation function that might add weight to high value patterns and ignore low value patterns.

MLP, which is one of the neural network's architecture, is a feed forward network with one or more layers of nodes between the input and output nodes. The additional layers contain hidden units or nodes that are not directly connected to both the input and output nodes. It is a supervised learning process with back propagation that feeds the errors between predicted and actual outputs backwards through the network to adjust the weights on the network connections.

In this study, a structured design approach recommended by Turban (1992) for developing neural network applications was adopted. The housing data are of terrace houses in KL, spanning the period from 1991 to 1996. Nine variables which were used in determining the house price are the year the data was collected, land area, house type, type of land ownership, built up area, age of the house, distance from the city, environment and building quality. The nine variables are the same as those used by INSPEN (1996) to produce the Malaysian house price index. 
Binary patterns have been used to represent the data as MLP processing elements produced output signals that vary in magnitude, usually in the range of 0 and 1 . Binary patterns are the easiest patterns to represent a network because they provide a very direct method of representing an input pattern. Several important decisions are required in MLP modelling such as the topology, i.e., number of processing elements and their configurations (input, layer, output), size of training and test data, network tool, learning algorithm and the activation function. The input layer consists of nodes that represent the nine variables mentioned earlier. The output layer has only one node which represents the price of the house.

In principle, the more examples or input data used for training, the better the model obtained. An increase in the number of observations will lead to a proportional decrease in noise effects. In this study 100 inputs from three years (i.e., 1994, 1995, 1996) have been used as exemplars giving a total of $\mathbf{3 0 0}$ inputs. $80 \%$ of the inputs were used as training data, $15 \%$ as validation data and $5 \%$ as test data (SPSS Inc, 1997). The selection of learning algorithm influences how well a neural network is able to solve a problem. The conjugate learning algorithm has been used in building the network in conjunction with the nature of the inputs. It measures the gradient of the error surface after each pass. The algorithm then alters the weights of the node inputs using a compromise between the direction of the steepest gradient and the previous direction of change. Three activation functions were used for trial in developing the model. They are the linear function, sigmoid function and the hyperbolic tangent function (Skapura, 1995).

The goal of building a network is not to memorise the training set but to learn something about the past that will generalise in the future when given a new example of the problem. The training process can be excessive and the best way to represent input data and the choice of architecture is subject to trial and error. Figure 1 shows the model structure of the network.

\section{ANALYSIS OF RESULTS}

Various different models were obtained in the training process. The criterion of choosing the optimum/best model using this network is based on the highest percentage of prediction. The best model obtained used the conjugate gradient as the learning algorithm and the linear activation function with one hidden layer and five hidden nodes, which have resulted in a $100 \%$ correct prediction. The associated root mean square (RMS) is 0.061717 which gives the mean square error (MSE) of 0.0038089 . The small error statistic indicates that the trained MLP network has a very good simulation fit. Table 1 depicts part of the modelling phase performed while obtaining the best model. However, the model had to be tested for its validity with different sets of test data.

Test sets were presented to the trained network for testing the predictive performance of the best model obtained. Table 2 shows the results for four different years when data were presented for testing using the MLP and multiple regression (MR) approaches. Multiple regression is a classical statistical method that fits the examples to a straight line or plane. The algorithm estimates the equation of the line or plane by finding the lowest error measure for the examples (SPSS Inc, 1997). The regression model used was,

$y=$

$$
\begin{aligned}
& 0.004613 x_{1}+0.36482 x_{2}+0.05108 x_{3}+0.03805 \\
& x_{4}+0.24442 x_{5}+0.02651 x_{6}-0.20767 x_{4}+ \\
& 0.09402 x_{8}+0.05726 x_{9}-92.04159
\end{aligned}
$$

where the dependent variable is the price, represented by $y$. The independent variables are as mentioned earlier, represented by $x_{1}, x_{2}$ ... $x_{9}$ respectively. This is the same model used by INSPEN (1996). All MSE values obtained from the two approaches fulfilled the required error of less than 0.01 , except for 1997. However the values obtained for 1997 still indicated a small error that can be accepted. The MSE values obtained from the MLP approach provided a better result than the one from regression. Figures 2 and 3 depict the graphs for the targeted and the predicted output for 100 data from 1996 and 1997. The 1997 housing data used for the testing and the predicted price obtained are shown in the Appendix. 
Figure 1

The Network Model Structure
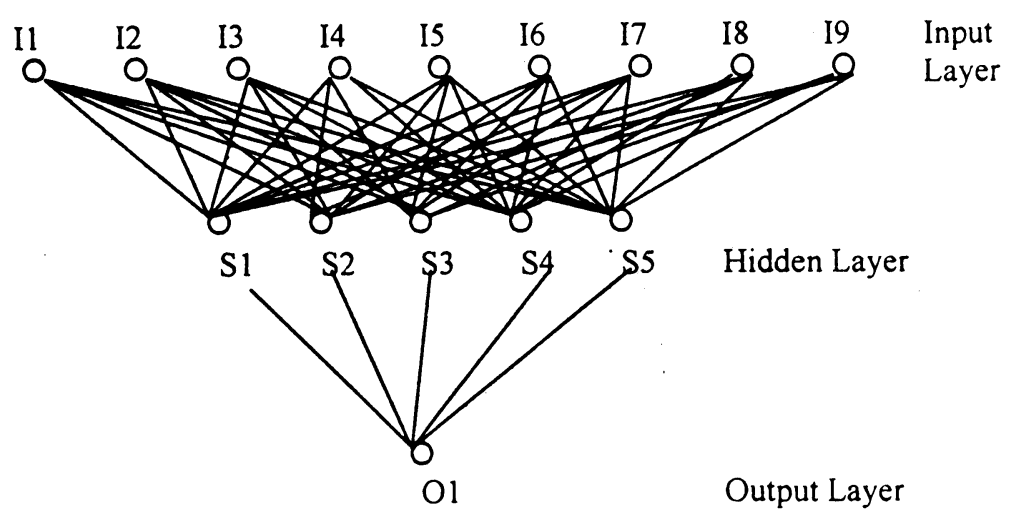

Table 1

MLP Modelling Process

\begin{tabular}{|l|l|l|l|l|l|c|}
\hline Model & Act.funct & Learn.algo & Distribution & RMS & Mean Abs & \% Prediction \\
\hline $1(9-3-1)$ & sigmoid & conj.grad & standard & 0.071315 & 0.054999 & 80.00 \\
$2(9-4-1)$ & sigmoid & conj.grad & standard & 0.061517 & 0.048291 & 86.67 \\
$3(9-5-1)$ & sigmoid & conj.grad & standard & 0.081211 & 0.057658 & 80.00 \\
$4(9-6-1)$ & sigmoid & conj.grad & standard & 0.076261 & 0.060379 & 86.67 \\
$5(9-7-1)$ & sigmoid & conj.grad & standard & 0.082582 & 0.054931 & 80.00 \\
$6(9-3-1)$ & tanh & conj.grad & standard & 0.073867 & 0.053065 & 86.67 \\
$7(9-4-1)$ & tanh & conj.grad & standard & 0.059695 & 0.045983 & 86.67 \\
$8(9-5-1)$ & tanh & conj.grad & standard & 0.111897 & 0.087805 & 66.67 \\
$9(9-6-1)$ & tanh & conj.grad & standard & 0.093520 & 0.063304 & 80.00 \\
$10(9-7-1)$ & tanh & conj.grad & standard & 0.128567 & 0.079643 & 73.33 \\
$11(9-3-1)$ & linear & conj.grad & standard & 0.061668 & 0.049229 & 93.33 \\
$12(9-4-1)$ & linear & conj.grad & standard & 0.062770 & 0.045233 & 86.67 \\
$13(9-5-1)$ & linear & conj.grad & standard & 0.061717 & 0.049156 & 100.00 \\
$14(9-6-1)$ & linear & conj.grad & standard & 0.061476 & 0.048923 & 93.33 \\
$15(9-7-1)$ & linear & conj.grad & standard & 0.061406 & 0.048699 & 93.33 \\
& & & & & \\
\hline
\end{tabular}

Multi Layer Perceptron Modelling Housing Market

Type of NN : MLP - multilayer perceptron

Learning Algorithm: i) steepest descent ii) conjugate gradient

Activation function: i) linear ii) hyperbolic tangent iii) sigmoid

Num. of data : $\quad 100$ from each year $(94,95,96)=300$ training data

Data Allocation: $\quad 80 \%$ - training, $15 \%$-validation, $5 \%$ - test 
Table 2

The MSE Result of Test Data

\begin{tabular}{|l|l|l|l|}
\hline \multirow{2}{*}{ Year } & \multirow{2}{*}{ Data Size } & \multicolumn{2}{|c|}{ MSE } \\
\cline { 3 - 4 } & & MLP & MR \\
\hline 1994 & 600 & 0.00393500 & 0.0048104 \\
\hline 1995 & 600 & 0.00447900 & 0.0076862 \\
\hline 1996 & 100 & 0.00139988 & 0.0026157 \\
\hline 1997 & 100 & 0.01496900 & 0.0174810 \\
\hline
\end{tabular}

Figure 2

Predicted vs Actual House Prices for 1996

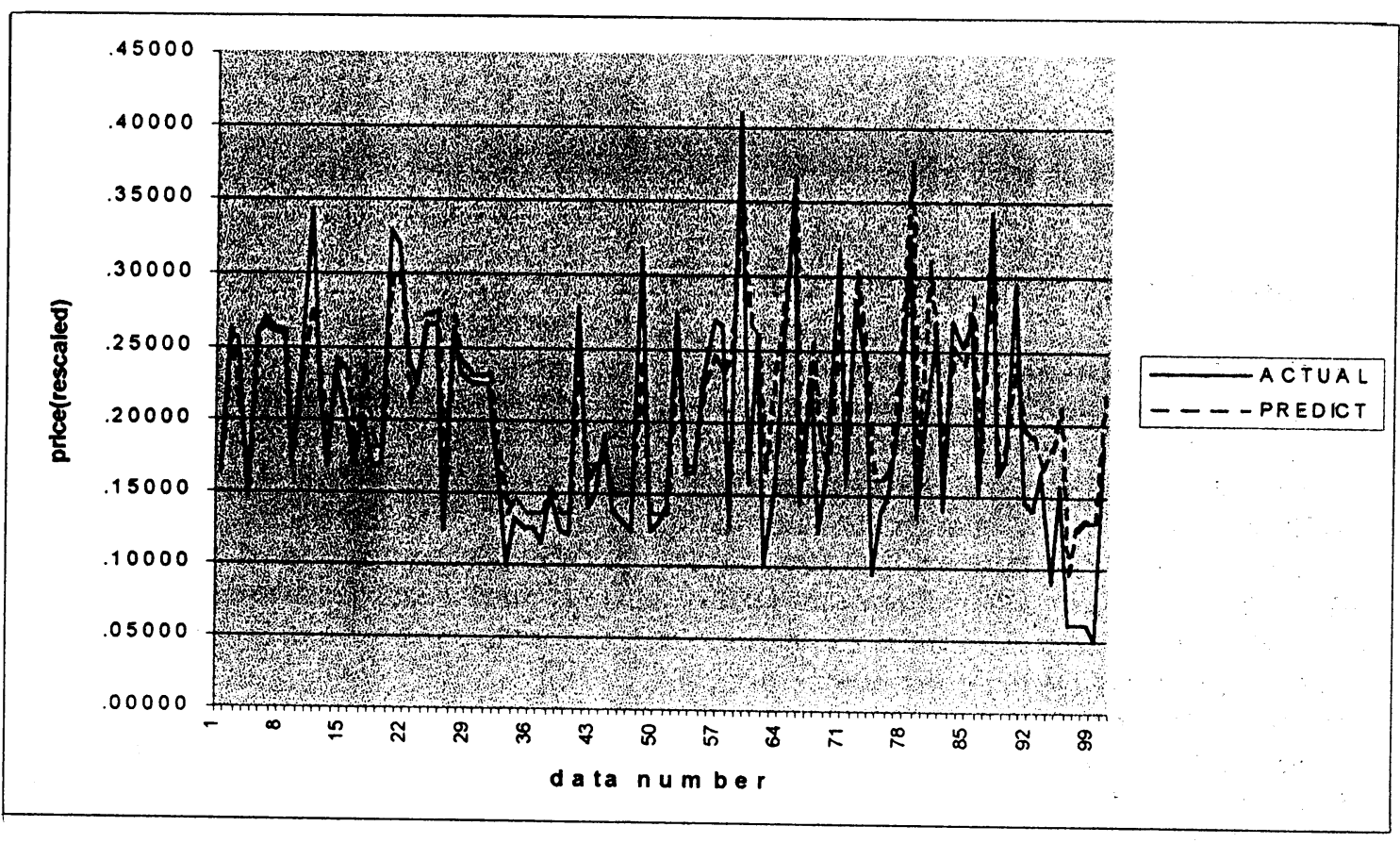




\section{Figure 3}

Predicted vs Actual House Prices for 1997

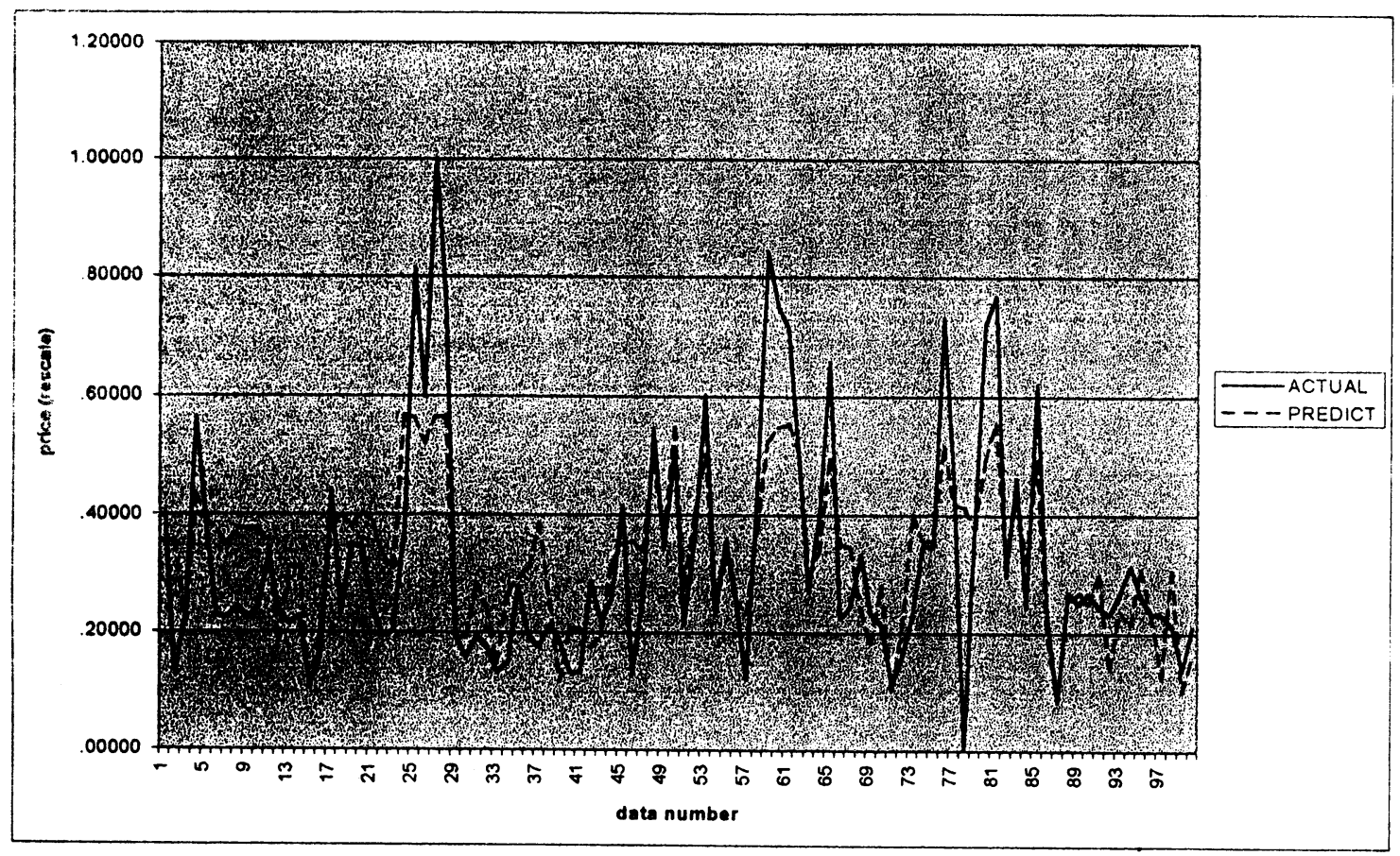

\section{CONCLUSION AND RECOMMENDATION}

This study shows that the MLP network can be used in modelling the Malaysian housing market and can be a useful and efficient way of modelling and analysing real estate markets to optimise allocation of resources. The results obtained from MLP are comparable to the one obtained by regression. This shows that MLP possesses considerable potential as an alternative to regression models. Further work on the MLP can be done to prove or test the generality of the model obtained. This can be done by providing test data sets of terrace houses from various states and years.

\section{REFERENCES}

Baestaens, D.E., Van Den Bagh, W.M. \& Wood, D. (1994). Neural Network Solutions for Trading in Financial Market, New Jersey: Pitman.
Chapman, A.J. (1994). Stock Market Trading Systems through Neural Networks: Developing a Model, International Journal of Applied Expert Systems, 2(2): 90 -99.

Hardgrave, B.L.C., Wilson, R.L. \& Walstrom, K.A. (1994). Predicting Graduate Student Success: A Comparison of Neural Networks and Traditional Techniques, Computers Operational Research, 21 (3): 249 $-263$.

INSPEN (1996). Malaysian House Price Index: $A$ Technical Summary, Kuala Lumpur: Ministry of Finance Malaysia.

Neural Connection 2.0 User's Guide (1997). Chicago: SPSS Inc/ Recognition Systems Inc.

Patterson, W. D. (1996). Artificial Neural Networks, Theory and Applications, Prentice Hall: Singapore. 
Richeson, L., Zimmerman, A.R. \& Barnett, K.G. (1994).Predicting Consumer CreditPerformance: Can Neural Networks Outperform Traditional Statistical Methods?, International Journal of Applied Expert Systems, 2(2): 115 - 129.

Saiful Hafizah, SitiMariyam Shamsudin, Noriza Majid \& Noriszura Ismail (1996). Analisis Pelaburan Saham Dengan Rangkaian Neural, Prosiding Simposium Kebangsaan Sains
Matematik ke VII, organised by Institut Teknologi MARA \& Persatuan Matematik Malaysia, 369 - 375.

Skapura, D.M. (1995). BuildingNeural Netwonks, New York: Addison Wesley.

Turban, E. (1992). Expert Systems and Applied Artificial Intelligence, New York: MacMillan Publication Co.

\section{APPENDIX}

\begin{tabular}{|c|c|c|c|c|c|c|c|c|c|c|c|}
\hline & Year & Larea & H/type & O/ship & B/area & Age & Dist & Aqulty & B/qlty & Aprice & P/price \\
\hline 1 & 1997 & 121 & 0.67 & 0 & 122 & 5 & 12 & 1.00 & 1.00 & 245500 & 217402 \\
\hline 2 & 1997 & 184 & 0.00 & 1 & 74 & 14 & 10 & 1.00 & 1.00 & 95000 & 216592 \\
\hline 3 & 1997 & 55 & 0.67 & 1 & 85 & 7 & 17 & 1.00 & 1.00 & 150000 & 138773 \\
\hline 4 & 1997 & 262 & 0.67 & 0 & 129 & 7 & 17 & 1.00 & 1.00 & 330000 & 259652 \\
\hline 5 & 1997 & 174 & 0.67 & 0 & 136 & 12 & 16 & 1.00 & 1.00 & 230000 & 236496 \\
\hline 6 & 1997 & 134 & 0.67 & 1 & 135 & 0 & 17 & 1.00 & 1.00 & 147750 & 224503 \\
\hline 7 & 1997 & 130 & 0.67 & 1 & 127 & 0 & 17 & 1.00 & 1.00 & 146000 & 214065 \\
\hline 8 & 1997 & 130 & 0.67 & 1 & 160 & 0 & 18 & 0.50 & 1.00 & 156000 & 227959 \\
\hline 9 & 1997 & 130 & 0.67 & 1 & 160 & 0 & 18 & 0.50 & 1.00 & 146000 & 227959 \\
\hline 10 & 1997 & 130 & 0.67 & 1 & 160 & 0 & 18 & 0.50 & 1.00 & 156000 & 227959 \\
\hline 11 & 1997 & 227 & 0.00 & 0 & 98 & 17 & 16 & 1.00 & 1.00 & 205000 & 210900 \\
\hline 12 & 1997 & 55 & 0.67 & 0 & 93 & 6 & 18 & 1.00 & 1.00 & 151000 & 123291 \\
\hline 13 & 1997 & 134 & 0.67 & 1 & 126 & 0 & 18 & 0.50 & 1.00 & 140363 & 192848 \\
\hline 14 & 1997 & 134 & 0.67 & 1 & 126 & 0 & 18 & 0.50 & 1.00 & 147750 & 192848 \\
\hline 15 & 1997 & 82 & 0.67 & 1 & 55 & 11 & 18 & 0.50 & 0.50 & 86000 & 80879 \\
\hline 16 & 1997 & 88 & 0.67 & 1 & 88 & 11 & 15 & 0.50 & 0.50 & 110000 & 136332 \\
\hline 17 & 1997 & 292 & 0.00 & 0 & 94 & 5 & 16 & 1.00 & 1.00 & 264000 & 229563 \\
\hline 18 & 1997 & 223 & 0.67 & 0 & 120 & 0 & 15 & 1.00 & 1.00 & 150000 & 240789 \\
\hline 19 & 1997 & 161 & 0.67 & 0 & 130 & 2 & 14 & 1.00 & 1.00 & 213500 & 230918 \\
\hline 20 & 1997 & 189 & 0.67 & 0 & 130 & 2 & 14 & 1.00 & 1.00 & 212000 & 243257 \\
\hline 21 & 1997 & 130 & 0.67 & 1 & 160 & 0 & 17 & 0.50 & 1.00 & 156000 & 233640 \\
\hline 22 & 1997 & 133 & 0.67 & 0 & 130 & 3 & 17 & 1.00 & 1.00 & 130000 & 202044 \\
\hline 23 & 1997 & 164 & 0.67 & 0 & 109 & 0 & 17 & 1.00 & 1.00 & 133888 & 191520 \\
\hline 24 & 1997 & 317 & 0.67 & 0 & 160 & 2 & 14 & 1.00 & 1.00 & 224440 & 332179 \\
\hline 25 & 1997 & 167 & 0.67 & 1 & 176 & 12 & 10 & 1.00 & 1.00 & 465000 & 328853 \\
\hline 26 & 1997 & 179 & 0.00 & 1 & 178 & 18 & 14 & 1.00 & 1.00 & 350000 & 306318 \\
\hline 27 & 1997 & 174 & 0.67 & 1 & 160 & 20 & 8 & 1.00 & 1.00 & 565000 & 329690 \\
\hline 28 & 1997 & 178 & 0.67 & 1 & 157 & 24 & 8 & 1.00 & 1.00 & 440000 & 330068 \\
\hline 29 & 1997 & 133 & 0.00 & 0 & 75 & 26 & 14 & 0.50 & 0.50 & 128000 & 126666 \\
\hline 30 & 1997 & 52 & 0.67 & 1 & 80 & 10 & 12 & 0.50 & 0.50 & 110000 & 128361 \\
\hline 31 & 1997 & 176 & 0.00 & 0 & 88 & 17 & 16 & 1.00 & 1.00 & 130000 & \begin{tabular}{|l|}
177582 \\
\end{tabular} \\
\hline 32 & 1997 & 149 & 0.00 & 1 & 83 & 27 & 15 & 0.50 & 0.50 & 120000 & 155205 \\
\hline 33 & 1997 & 55 & 0.67 & 1 & 57 & 8 & 12 & 0.50 & 0.50 & 97000 & 103802 \\
\hline 34 & 1997 & 137 & 0.00 & 1 & 76 & 23 & 10 & 0.50 & 0.50 & 105000 & 168824 \\
\hline 35 & 1997 & 143 & 0.00 & 1 & 95 & 28 & 12 & 0.50 & 0.50 & 175000 & 183069 \\
\hline 36 & 1997 & 149 & 0.00 & 1 & 101 & 28 & 12 & 0.50 & 0.50 & 130000 & 192211 \\
\hline 37 & 1997 & 148 & 0.67 & 1 & 127 & 34 & 12 & 0.50 & 0.50 & 120000 & 232873 \\
\hline 38 & 1997 & 127 & 0.00 & 11 & 99 & 24 & 15 & 0.50 & 0.50 & 140000 & 161447 \\
\hline 39 & 1997 & 82 & 0.67 & 0 & 88 & 11 & 20 & 0.50 & 0.50 & 125000 & 87300 \\
\hline 40 & 1997 & 66 & 0.67 & 1 & 62 & 8 & 8 & 0.50 & 0.50 & 96000 & 136775 \\
\hline 41 & 1997 & 133 & 0.00 & 0 & 83 & 27 & 14 & 0.50 & 0.50 & 97000 & 135819 \\
\hline 42 & 1997 & 82 & 0.67 & 0 & 89 & 16 & 15 & 0.50 & 0.50 & 180000 & 119111 \\
\hline 43 & 1997 & 55 & 0.67 & 1 & 80 & 10 & 12 & 0.50 & 0.50 & 143000 & 129679 \\
\hline
\end{tabular}




\begin{tabular}{|c|c|c|c|c|c|c|c|c|c|c|c|}
\hline 44 & \begin{tabular}{|l|}
1997 \\
\end{tabular} & 100 & 0.67 & 1 & 94 & 8 & 12 & 1.00 & 1.00 & 165000 & 197195 \\
\hline 45 & \begin{tabular}{|l|}
1997 \\
\end{tabular} & 155 & 0.67 & 0 & 147 & 4 & 14 & 0.50 & 0.50 & 250000 & 214200 \\
\hline 46 & 1997 & 184 & 0.00 & 1 & 74 & 14 & 10 & 1.00 & 1.00 & 95000 & 216592 \\
\hline 47 & 1997 & 108 & 0.67 & 1 & 101 & 7 & 12 & 1.00 & 1.00 & 162888 & 207849 \\
\hline 48 & 1997 & 196 & 0.67 & 0 & 155 & 13 & 6 & 0.50 & 0.50 & 320000 & 290556 \\
\hline 49 & 1997 & 106 & 0.67 & 1 & 131 & 3 & 15 & 1.00 & 1.00 & 210000 & 220583 \\
\hline 50 & \begin{tabular}{|l|}
1997 \\
\end{tabular} & 305 & 0.67 & 1 & 129 & 10 & 13 & 1.00 & 1.00 & 300000 & 320715 \\
\hline 51 & 1997 & 82 & 0.67 & 1 & 97 & 17 & 10 & 0.50 & 0.50 & 140000 & 174639 \\
\hline 52 & 1997 & 116 & 0.67 & 1 & 130 & 25 & 8 & 0.50 & 0.50 & 220000 & 240503 \\
\hline 53 & 1997 & 254 & 0.67 & 1 & 131 & 13 & 14 & 1.00 & 1.00 & 350000 & 296150 \\
\hline 54 & 1997 & 55 & 0.67 & 0 & 93 & 7 & 7 & 0.50 & 0.50 & 150000 & 152721 \\
\hline 55 & 1997 & 108 & 0.67 & 1 & 102 & 7 & 12 & 1.00 & 1.00 & 218000 & 208924 \\
\hline 56 & 1997 & 82 & 0.67 & 1 & 97 & 17 & 12 & 0.50 & 0.50 & 165000 & 163280 \\
\hline 57 & 1997 & 55 & 0.67 & 0 & 83 & 14 & 6 & 0.50 & 0.50 & 90000 & 150847 \\
\hline 58 & 1997 & 250 & 0.00 & 1 & 92 & 28 & 12 & 0.50 & 0.50 & 260000 & 226944 \\
\hline 59 & 1997 & 199 & 0.67 & 1 & 176 & 10 & 16 & 1.00 & 1.00 & 480000 & 307955 \\
\hline 60 & 1997 & 178 & 0.67 & 1 & 127 & 25 & 4 & 1.00 & 1.00 & 430000 & 320704 \\
\hline 61 & 1997 & 223 & 0.67 & 1 & 157 & 4 & 11 & 1.00 & 1.00 & 410000 & 323485 \\
\hline 62 & 1997 & 149 & 0.67 & 1 & 166 & 15 & 12 & 1.00 & 1.00 & 300000 & 300141 \\
\hline 63 & 1997 & 153 & 0.67 & 0 & 145 & 19 & 20 & 0.50 & 0.50 & 170000 & 184149 \\
\hline 64 & 1997 & 174 & 0.67 & 0 & 168 & 18 & 22 & 0.50 & 0.50 & 240000 & 206516 \\
\hline 65 & 1997 & 175 & 0.67 & 1 & 146 & 20 & 12 & 1.00 & 1.00 & 380000 & 292251 \\
\hline 66 & 1997 & 130 & 0.67 & 1 & 127 & 1 & 17 & 1.00 & 1.00 & 146000 & 214529 \\
\hline 67 & 1997 & 130 & 0.67 & 1 & 160 & 1 & 18 & 0.50 & 0.50 & 156000 & 211187 \\
\hline 68 & 1997 & 98 & 0.00 & 0 & 98 & 17 & 16 & 1.00 & 1.00 & 205000 & 154065 \\
\hline 69 & 1997 & 55 & 0.67 & 0 & 93 & 6 & 18 & 1.00 & 1.00 & 151000 & 123291 \\
\hline 70 & 1997 & 134 & 0.67 & 1 & 126 & 1 & 18 & 0.50 & 0.50 & 140363 & 176076 \\
\hline 71 & 1997 & 82 & 0.67 & 1 & 55 & 11 & 18 & 0.50 & 0.50 & 86000 & 80879 \\
\hline 72 & 1997 & 88 & 0.67 & 1 & 88 & 11 & 15 & 0.50 & 0.50 & 110000 & 136332 \\
\hline 73 & 1997 & 223 & 0.67 & 0 & 120 & 1 & 15 & 1.00 & 1.00 & 150000 & 241259 \\
\hline 74 & 1997 & 130 & 0.67 & 0 & 130 & 2 & 14 & 1.00 & 1.00 & 213500 & 217267 \\
\hline 75 & 1997 & 130 & 0.67 & 0 & 130 & 2 & 14 & 1.00 & 1.00 & 212000 & 217267 \\
\hline 76 & 1997 & 167 & 0.67 & 1 & 165 & 19 & 13 & 1.00 & 1.00 & 420000 & 303181 \\
\hline 77 & 1997 & 143 & 0.67 & 1 & 151 & 23 & 12 & 0.50 & 0.50 & 275000 & 251535 \\
\hline 78 & 1997 & 153 & 0.67 & 0 & 161 & 20 & 12 & 0.50 & 0.50 & 25000 & 247361 \\
\hline 79 & 1997 & 153 & 0.67 & 1 & 132 & 19 & 13 & 0.50 & 0.50 & 230000 & 227781 \\
\hline 80 & 1997 & 149 & 0.67 & 1 & 177 & 19 & 10 & 0.50 & 0.50 & 415000 & 291825 \\
\hline 81 & 1997 & 184 & 0.67 & 1 & 184 & 6 & 13 & 1.00 & 1.00 & 440000 & 325170 \\
\hline 82 & 1997 & 122 & 0.00 & 1 & 122 & 27 & 12 & 0.50 & 0.50 & 185000 & 202617 \\
\hline 83 & 1997 & 143 & 0.67 & 1 & 151 & 11 & 10 & $0.5 \%$ & 0.50 & 275000 & 257254 \\
\hline 84 & 1997 & 149 & 0.00 & 1 & 96 & 29 & 10 & 0.50 & 0.50 & 156000 & 198599 \\
\hline 85 & 1997 & 147 & 0.67 & 1 & 177 & 19 & 10 & 0.50 & 0.50 & 360000 & 290945 \\
\hline 86 & 1997 & 82 & 0.67 & 1. & 80 & 4 & 14 & 0.50 & 0.50 & 150000 & 127395 \\
\hline 87 & 1997 & 51 & 0.67 & 0 & 56 & 19 & 15 & 0.50 & 0.50 & 70000 & 71089 \\
\hline 88 & 1997 & 92 & 0.67 & 0 & 103 & 4 & 10 & 0.50 & 0.50 & 170000 & 161436 \\
\hline 89 & 1997 & 139 & 0.00 & 0 & 117 & 4 & 16 & 1.00 & 0.50 & 160000 & 169385 \\
\hline 90 & 1997 & 143 & 0.00 & 1 & 90 & 25 & 15 & 0.50 & 0.50 & 169000 & 159212 \\
\hline 91 & 1997 & 98 & 0.67 & 0 & 98 & 2 & 8 & 0.50 & 1.00 & 157000 & 186309 \\
\hline
\end{tabular}

Malaysian Management Journal 3 (1), 61 - 69 (1999) 


\begin{tabular}{|r|r|r|r|r|r|r|r|r|r|r|r|}
\hline 92 & 1997 & 82 & 0.00 & 0 & 88 & 11 & 16 & 0.50 & 0.50 & 150000 & 99898 \\
\hline 93 & 1997 & 133 & 0.00 & 1 & 75 & 19 & 12 & 0.50 & 0.50 & 170000 & 152748 \\
\hline 94 & 1997 & 82 & 0.67 & 1 & 100 & 11 & 16 & 0.50 & 0.50 & 195000 & 141014 \\
\hline 95 & 1997 & 145 & 0.00 & 1 & 89 & 34 & 10 & 0.50 & 0.50 & 168000 & 191612 \\
\hline 96 & 1997 & 109 & 0.67 & 0 & 83 & 13 & 10 & 0.50 & 0.50 & 152000 & 151473 \\
\hline 97 & 1997 & 82 & 0.67 & 1 & 55 & 11 & 16 & 0.50 & 0.50 & 150000 & 92230 \\
\hline 98 & 1997 & 137 & 0.67 & 1 & 85 & 27 & 10 & 0.50 & 0.50 & 140000 & 190559 \\
\hline 99 & 1997 & 55 & 0.67 & 1 & 57 & 7 & 16 & 0.50 & 0.50 & 100000 & 80625 \\
\hline 100 & 1997 & 55 & 0.67 & 1 & 80 & 8 & 15 & 0.50 & 0.50 & 138000 & 111713 \\
\hline
\end{tabular}

$\begin{array}{lll}\text { L/area } & - & \text { Land area } \\ \text { H/type } & - & \text { House type } \\ \text { O/ship } & - & \text { Type of ownership } \\ \text { A/qlty } & - & \text { Area quality } \\ \text { B/qlty } & - & \text { Building quality } \\ \text { A/price } & - & \text { Actual price } \\ \text { P/price } & - & \text { Predicted price }\end{array}$

